\title{
An Exploratory Analysis of Factors Associated with Low Risk Perception for Developing Type 2 Diabetes amongst Low-income, Primarily Latina Women with prior Gestational Diabetes Mellitus
}

Priyanka Athavale ( $\square$ priyanka222@gmail.com )

UCSF Medical Center https://orcid.org/0000-0002-5968-350X

Ndola Prata

University of California Berkeley School of Public Health

Karen Sokal-Gutierrez

University of California Berkeley School of Public Health

Maureen Lahiff

University of California Berkeley School of Public Health

Adriana Najmabadi

University of California San Francisco Department of Epidemiology and Biostatistics

Jared Landeros

University of California, San Francisco Department of Epidemiology and Biostatistics

Christina Rios

University of California, San Francisco Department of Epidemiology and Biostatistics

Judy Quan

University of California San Francisco Department of Epidemiology and Biostatistics

Margaret A Handley

University of California, San Francisco Division of General Internal Medicine, Center for Vulnerable Populations

\section{Research article}

Keywords: Diabetes Mellitus, Maternal Health, Risk Assessment, Emigrants and Immigrants, Hispanic Americans, Primary Prevention, Chronic Disease

Posted Date: January 16th, 2020

DOI: https://doi.org/10.21203/rs.2.21040/v1

License: (c) (i) This work is licensed under a Creative Commons Attribution 4.0 International License. Read Full License 
Page $2 / 25$ 


\section{Abstract}

Background: Gestational diabetes mellitus (GDM) is a significant contributor to the development of diabetes (DM2) post-partum, with higher rates amongst low-income and Latina women. Understanding one's risk perception for developing DM2 postpartum amongst women with GDM can help target preventive interventions that promote positive health behaviors and lifestyle changes. This study aims to assess how the interplay of individual level factors, healthcare based factors, and structural factors influence risk perception for developing DM2 amongst low-income, primarily migrant Latina women with recent gestational diabetes mellitus.

Methods: Data is from the baseline assessment of the STAR MAMA intervention. Women $(\mathrm{N}=171)$ receiving prenatal care at low-income urban clinics in San Francisco Bay Area were surveyed for basic demographics, healthcare access, and health-related behaviors. The outcome variable, risk perception for developing DM2 post-partum, was measured using the RPS-DM tool. Associations between risk perception for developing DM2 and individual, health-care based and structural (eg. health insurance, food insecurity, educational attainment) covariates were estimated using descriptive statistics and logistic regression.

Results: Although all participants had a high risk for subsequently developing DM2, 76\% reported lower risk perception for developing diabetes within the next 1, 5, and 10 years. Migrant status, less than high school education, and food insecurity were associated with lower risk perception $(p<0.05)$. Spanishspeaking women with GDM who did not have family histories of DM2 were at greatest risk of underestimating their $\mathrm{DM} 2$ risk $(\mathrm{OR}=6.5 ; \mathrm{Cl}=(1.149,11.795))$. On the other hand, Spanish-speaking women who had family histories of DM2 were more likely to correctly assess their $\mathrm{DM} 2$ risk $(\mathrm{OR}=0.16 ; \mathrm{Cl}=$ $(0.031,0.824))$.

Conclusions: Structural and individual factors, rooted in migrant status and cultural backgrounds, influence personal risk perception. The majority of high-risk GDM women in this sample underestimate their risk for developing diabetes. This poses an opportunity for the healthcare system to improve patientprovider communication to improve risk perceptions and motivation for behavioral risk reduction. Improved counseling regarding risk perception for vulnerable, migrant populations with GDM is critical to accurately convey risk and engage individuals in preventive behaviors. Trial Registration: The clinical trial registration number is: NCT02240420 and date of registration: 9/11/2014.

\section{Introduction}

Gestational diabetes mellitus (GDM) is defined as impaired glucose tolerance with onset or recognition during pregnancy [1]. GDM affects $9-26 \%$ of pregnancies, with higher prevalence amongst older, Hispanic, and overweight/obese patients [2]. Women with GDM have a sevenfold increased risk for developing Type 2 Diabetes (DM2) compared to those without GDM [3, 4, 5]. 
One of the strongest non-modifiable risk factors for developing diabetes post GDM is a woman's ethnicity. In California and in the United States, Latinos are the largest minority group, with the highest birth and immigration rates of any minority group. A study showed that after controlling for known risk factors, first generation Hispanic/Latina women had a 59\% increased risk for GDM compared to non-Latina women [6]. Latinas develop GDM at a $66 \%$ higher rate than non-Latinas, and have a $60 \%$ increased risk of developing DM2 within 5 years of a GDM pregnancy $[6,7]$. Despite the high rates of progression of GDM to type 2 diabetes, only one in five Latina women receive recommended postpartum diabetes screening, the lowest follow-up frequency for any ethnic group [8]. Between 2000 and 2010, Latina women have experienced the highest relative increase in GDM prevalence, at 66\% [9].

For women with GDM, DM2 is preventable through lifestyle interventions $[8,9,10,11,12,13]$. Patients' risk perception-their subjective assessment of the probability and severity of disease-enhances their attendance and engagement with interventions promoting preventive behaviors $[13,14,15,16,17,18]$. A study of Caucasian women with GDM found that $90 \%$ agreed that GDM was a risk factor for developing DM2, but only $16 \%$ believed they were at high risk for developing DM2 [19]. A study by Joiner et. al conducted in San Francisco in 2014 studied risk perception for developing diabetes amongst foreign born migrants to the US. Out of 146 participants, $16 \%$ of reported high risk perception for developing diabetes, and $31.5 \%$ had a perception of moderate or high risk [20]. Many women felt their risk for diabetes was inevitable since the disease in in their family and their diet included chocolates and sweets [21]. Among Latinas, GDM history, high school degree, and having a greater degree of worry were associated with higher risk perception for developing DM2 [20]. Current data illustrate a discordance between one's known increased risk for DM2 given a known diagnosis of GDM and one's personal risk perception for developing DM2. This disparity in actual risk versus perceived risk is an important point of intervention to enable GDM positive women to engage in health behavior change post-partum.

One of the key influencers of behavior change according to health behavior change theories, such as the Health Belief Model, Social Cognitive Theory and Transtheoretical Model, is risk perception [22, 23]. Risk perception is a concept derived from the Health Belief Model (HBM), and measures one's subjective assessment of the probability and severity of disease. Previous studies amongst patient groups have found that increased risk perception enhances attendance and engagement with intervention [16]. Theoretical approaches inform behavior change interventions to prevent DM2, and focus on risk perceptions as a critical step to reducing diabetes risk [17]. Although established health behavior change theories such as the Health Belief Model, Trans-Theoretical Model, and Social Cognitive Theory illustrate the role of risk perception for health behavior change at the individual level, they do not address the role of structural and community-level factors in impacting an individuals' perceived susceptibility. Using solely these individual level factors to determine and predict risk perception fails to recognize that many of the underlying socio-ecological conditions that affect the migrant patient.

In the context of women with GDM, we hypothesize that in addition to individual factors, healthcare based and structural level factors could also contribute to one's personal risk perception for developing type 2 diabetes postpartum. Our hypothesis is informed by the WHO Conceptual Framework for Social 
and Structural Determinants of Health and the Ecosocial Theory by Nancy Krieger. The WHO Conceptual Framework for Social and Structural Determinants of Health Inequity (2010) posits that structural determinants of health operate through intermediary factors and determine differences in exposure and vulnerability to health-compromising conditions [24]. The structural determinants of health include differences in one's historical context and background, social and public policies affecting specific populations, cultural and societal values, and disparities in environmental exposures that influence overall health outcomes and access to health $[19,24]$. For highly vulnerable non-English speaking groups, we hypothesize that additional factors including food insecurity, social support, years living in the US, education, health insurance and other social and environmental factors could influence risk perception. The conceptual framework illustrates that structural factors (one's primary language, migrant status, educational attainment, income level, employment, food insecurity, months lived in neighborhood and health insurance), healthcare based factors (insulin use during pregnancy, family history of DM2, history of pre-DM2), and individual level factors (age, race, ethnicity, personal control and optimistic bias) contribute to risk perception. Understanding important cultural and lifestyle-related beliefs of Latin American migrants, and the heterogeneity that exists across different groups of migrants, is essential to understanding the disparities in diabetes knowledge, perceived risk, and behavior change.

The objective of this study is to assess the how interplay of individual level factors, healthcare based factors, and structural factors influence risk perception for developing diabetes mellitus amongst lowincome, primarily migrant Latina women with prior gestational diabetes mellitus.

\section{Methods}

This paper is a quantitative descriptive analysis of the baseline data from the STAR MAMA (support via Telephone Advice and Resources/Sistema Teléfonico de Apoyo y Recursos-MAMA; 2014-2018) intervention trial to identify factors that are associated with varying risk perception in the study population [25].

\section{Overview: STAR MAMA Intervention}

STAR MAMA was developed to examine the acceptability, feasibility, and effectiveness of a DPP (Diabetes Prevention Program)-adapted multilingual hybrid program on diabetes prevention outcomes among post-partum women with a recent diagnosis of GDM [26]. The pilot employs a randomized control design to compare the effects of a hybrid automated telephone messaging system and health coaching intervention on diabetes-focused outcomes among women with recent GDM. The goal of the intervention is to improve patient clinical outcomes such as BMI and weight loss, improve adherence to guidelines for glucose screening, and assess positive changes in reported self-care and diabetes prevention activities (i.e.: healthy diet, increased physical activity, improved mood), among low-income, post-partum women with recent GDM [26]. 
Baseline survey questions were asked of all participants in the study. Survey topics included: background and demographics, self-rated health, health literacy, food insecurity, current health-related activities, risk perceptions, family history, and neighborhood scale. The clinical trial registration number is:

NCT02240420. This research was approved by the Institutional Review Board of the University of San Francisco.

\section{Study Sample}

The study sample included women receiving prenatal care in publicly-funded community clinics: Zuckerberg San Francisco General Hospital (ZSFGH), San Francisco WIC, Sonoma County WIC, and Vista Clinic in Santa Rosa. Patients were recruited upon reviewing patient electronic medical records confirming a diagnosis of gestational diabetes. Site-specific records were accessed electronically to identify patients who (1) have a current or recent diagnosis of GDM, (2) are between the ages of 18 and 39 years, (3) speak English or Spanish, (4) do not have comorbidities such as psychosis or end-stage disease. The diagnosis of GDM is not determined through a strict clinical guideline, but rather it is based on a timely utilization of an oral glucose challenge test (GCT) [27]. Participants were identified as having GDM by their providers if they screened positively between 24-28 weeks gestation using ACOG guidelines [27]. Women who did not meet the above criteria were excluded from the study sample.

\section{Data Collection}

Primary and secondary patient-reported outcomes were derived from a structured interview that was conducted in Spanish or English after informed consent. Spanish interviews were translated from the English version and then back-translated to English to verify the equivalency. Interviews were administered in person for all baseline surveys at the time of enrollment of the participant. All eligible participants were enrolled and interviewed during their pregnancy after confirmation of GDM positive status.

\section{Variables}

\section{Outcome measure: Risk Perception}

Assessment of risk perception was conducted using the Risk Perception Survey for Developing Diabetes (RPS-DD) [28]. Subscales of the 8-item survey instrument for risk perception for Personal Control and Optimistic Bias were measured, including two questions about weight loss and overweightness relative to this population. Questions were asked on a 5-point Likert scale: Strongly Agree (1) to strongly disagree (5).

The risk perception variable was constructed using three items from survey questions used in the study Kim et al. ("What do you think is your risk or chance of getting diabetes over the next 1 year? 5 years? 10 years?"). The responses were on a 4-point Likert scale ranging from Almost None, Slight, Moderate, and High chance. Women who answered Almost None and Slight were categorized as having "Low Risk 
perception"; and Moderate to High were categorized as having "High Risk perception". Dichotomization was done based on prior studies of DM2 risk perception $[2,5,20]$.

\section{Covariates: Individual Level, Healthcare Related, and Structural Level}

Figure 1 depicts the conceptual model linking risk perception and behavior change variables. Covariates selected in the analysis were consistent with the conceptual framework were developed.

Individual level measures included: age, ethnicity, migrant status, personal control, and optimistic bias. Spanish speaking and migrant status was asked by asking the patient in the survey what primary language they spoke at home and if they had immigrated to the US from another country. The personal control subscale consists of 4 items in the Risk Perception Survey, and is scored from 1-4, with a higher score indicating higher personal control. This subscale was dichotomized to avoid small cell sizes. Optimistic bias was coded similarly. Health-care related measures were defined as factors within the realm of healthcare treatment, access, and health history. The covariates included: insulin use during pregnancy, history of pre-DM or overweight, and family history (of first degree relatives, a person's parent, sibling, or child) of DM2. Structural measures included: health insurance, education level, migrant status, primary language (language preferred at home), and length of time lived in neighborhood level. Length of time lived in neighborhood was asked in months, and the distribution of answers, based on quartiles was used to generate a categorical variable with four categories: 0-2 years, 2-4 years, 4-7 years and greater than 7 years. All outcomes were self-reported.

\section{Statistical Analysis}

Bivariate analysis between covariates and risk perception was conducted; associations with $p<0.10$ were selected for the multivariate logistic regression model. Because risk perception for developing DM2 over the next 1 year, 5, and 10 years was congruent, we used risk perception in one year as the main outcome in multivariate logistic regression. Chi square tests with $p<0.05$ were used to eliminate covariates that were highly correlated. Since the existing literature demonstrates that there are differences in risk for developing DM2 between Latinas and non-Latinas, we dichotomized these two groups in our study [19, $20,21]$. We used the variable "primary language" as a proxy for race/ethnicity since 1) primary language (as non-English) represents a structural barrier to accessing healthcare services and self-advocacy within the healthcare system and 2) ethnicity is often ascribed to an individual based on race/background, but not necessarily representative of their education, English language proficiency, and mobility in the healthcare system [29]. As such, we dichotomized the GDM positive women in this sample to "Spanish speaking" and "non-Spanish speaking". We hypothesized that a number of the covariates were associated with primary language, so we conducted logistic regression with each covariate and the cross product. Only the cross product of family history of DM2 and primary language as Spanish was statistically significant in the model, so we included this cross product in the final model. All analyses were conducted in STATA Copyright 1985-2015 StataCorp LP. 


\section{Results}

Descriptive statistics are presented in Table 1. Participants' mean age was 31.2 years; $78 \%$ identified as Hispanic or Latino, $62.5 \%$ of the participants' primary language was Spanish, $44.4 \%$ had a less than high school graduate education, and $56.1 \%$ have an annual household family income at less than $\$ 20,000$. The majority of the participants (79.5\%), identified as migrants and $42.1 \%$ reported living in their current neighborhood for less than 2 years. Approximately $59 \%$ reported food insecurity and $84.2 \%$ received Medi-Cal public health insurance. Regarding health-care based factors, $50.3 \%$ report a family history of DM2 amongst first-degree relatives, and $37.4 \%$ were prescribed insulin during their pregnancy to manage GDM. Only 55.8\% completed their glucose screening test prior to delivery, even though every participant in the study had a high glucose as evidenced by their diagnosis of GDM. Sixty-four percent were overweight, obese, or extremely obese based on their pre-gravid BMI. Fifty-eight percent reported low personal control and $81.3 \%$ had low optimistic bias. 
Table 1

Study Participant Characteristics ( $\mathrm{N}=171)$; 2017, University of California, San Francisco

\begin{tabular}{|ll|}
\hline Characteristic & Mean ( $\mathbf{S}$ SD*) or $\mathbf{n}(\%)$ \\
\hline Age (years) & $31.2 \pm 4.9$ \\
\hline Primary Language & $64(37.4)$ \\
\hline English & $107(62.6)$ \\
\hline Spanish & \\
\hline Ethnic Group & $134(78.4)$ \\
\hline Hispanic or Latino & $37(21.6)$ \\
\hline Non Hispanic/ Latino & $133(77.8)$ \\
\hline Race & $18(10.5)$ \\
\hline Latino/ Hispanic & $12(7.0)$ \\
\hline Asian or Pacific Islander & $8(4.6)$ \\
\hline Black or African American & \\
\hline White or Caucasian or Other & $34(19.9)$ \\
\hline Marital Status & $137(80.1)$ \\
\hline Never Married, Separated or Widowed & \\
\hline Married or living with a partner & $76(44.4)$ \\
\hline Educational attainment & $49(28.7)$ \\
\hline Less than high school or some high school & $46(26.9)$ \\
\hline High school graduate & \\
\hline College or more & \\
\hline Working Status & \\
\hline Working full time or part time & \\
\hline Homemaker & \\
\hline Unemployed or Other & \\
\hline Total Annual Household Income & \\
\hline Less than $\$ 20,000$ & \\
\hline
\end{tabular}




\begin{tabular}{|c|c|}
\hline Characteristic & Mean $\left( \pm \mathrm{SD}^{*}\right)$ or $\mathrm{n}(\%)$ \\
\hline$\$ 20,001$ or above & $55(32.2)$ \\
\hline Refused or Don't know & $20(11.7)$ \\
\hline \multicolumn{2}{|l|}{ Migrant } \\
\hline No & $35(20.5)$ \\
\hline Yes & $136(79.5)$ \\
\hline \multicolumn{2}{|l|}{ Time lived in Neighborhood } \\
\hline 0 to 2 years & $72(42.1)$ \\
\hline 2 to 4 years & $24(14.0)$ \\
\hline 4 to 7 years & $40(23.4)$ \\
\hline $7+$ years & $35(20.5)$ \\
\hline \multicolumn{2}{|l|}{ Health Insurance during Pregnancy } \\
\hline Medi Cal & $144(84.2)$ \\
\hline Multiple Insurance Plans & $15(8.8)$ \\
\hline A health plan paid for by Medi-cal & $6(3.5)$ \\
\hline Other Public Insurance (SF Health Plan or Healthy SF) or Private & $6(3.5)$ \\
\hline \multicolumn{2}{|l|}{ Practical Social Support Received During Pregnancy } \\
\hline Yes & $134(78.4)$ \\
\hline No & $37(21.6)$ \\
\hline \multicolumn{2}{|l|}{ Emotional Social Support Received During Pregnancy } \\
\hline Yes & $148(87.5)$ \\
\hline No & $21(12.4)$ \\
\hline \multicolumn{2}{|l|}{ Food Insecurity } \\
\hline Yes & $101(59.1)$ \\
\hline No & $70(40.9)$ \\
\hline \multicolumn{2}{|l|}{ Family History of DM2 } \\
\hline Yes & $86(50.3)$ \\
\hline
\end{tabular}




\begin{tabular}{|c|c|}
\hline Characteristic & Mean $\left( \pm \mathrm{SD}^{*}\right)$ or $\mathrm{n}(\%)$ \\
\hline No & $85(49.7)$ \\
\hline \multicolumn{2}{|c|}{ History of Obesity/unhealthy weight gain } \\
\hline Yes & $58(33.9)$ \\
\hline No & $113(66.1)$ \\
\hline \multicolumn{2}{|l|}{ History of Pre-diabetes } \\
\hline Yes & $16(9.4)$ \\
\hline No & $154(90.6)$ \\
\hline \multicolumn{2}{|c|}{ Use of Insulin During Pregnancy to manage GDM } \\
\hline Yes & $64(37.4)$ \\
\hline No & $107(62.6)$ \\
\hline \multicolumn{2}{|l|}{ BMI at time of Survey } \\
\hline Normal or Overweight & $49(41.8)$ \\
\hline Obese or Extremely Obese & $68(58.1)$ \\
\hline \multicolumn{2}{|c|}{ Glucose Screening Received prior to delivery } \\
\hline Yes & $67(55.8)$ \\
\hline No & $25(20.8)$ \\
\hline Ordered & $28(23.3)$ \\
\hline \multicolumn{2}{|c|}{ Attempted to change habits in the past 6 months } \\
\hline Yes & $156(91.2)$ \\
\hline No & $15(8.8)$ \\
\hline \multicolumn{2}{|c|}{ Intends to change habits in the next 6 months } \\
\hline Yes & $147(86.5)$ \\
\hline No & $23(13.5)$ \\
\hline \multicolumn{2}{|c|}{ Confidence towards changing health behaviors } \\
\hline Yes & $164(98.8)$ \\
\hline No & $1(0.6)$ \\
\hline
\end{tabular}




\begin{tabular}{|ll|}
\hline Characteristic & Mean $( \pm$ SD*) or $\mathbf{n}(\%)$ \\
\hline Personal Control & $2.26 \pm 0.4$ \\
\hline Optimistic Bias & $2.38 \pm 0.4$ \\
\hline *SD: Standard Deviation & \\
\hline
\end{tabular}

[Table 1]

The distribution of risk perception for type 2 diabetes within the next 1 year, 5 years, and 10 years was congruent upon analysis. Seventy-six percent of participants reported they had almost none to slight risk for developing type 2 diabetes over the next 1 year. When asked the same question for diabetes risk over the next 5 years and 10 years, the response was consistent at $76.6 \%$ and $71.3 \%$, respectively.

Table 2 shows associations between individual, healthcare based, and structural covariates and risk perception. Among individual level variables, identifying as a migrant, Hispanic ethnicity, and primary language as Spanish were significantly associated with low risk perception $(p<0.05)$. No healthcare related factors were significantly associated with low risk perception. Among the structural level variables, only high school education and food insecurity were significantly associated with low risk perception. The bivariate analysis showed that migrant status and educational level were highly associated with one another. Based on our framework and hypothesis that structural level factors could contribute to low risk perception, we decided to include only education in the multi-variate regression model. 
Table 2

Bivariate Analysis of Individual level, Health care based, and Structural level factors associated with Low Risk Perception ( $N=171) ; 2017$, University of California, San Francisco

\begin{tabular}{|c|c|c|c|}
\hline & $\begin{array}{l}\text { Low Risk } \\
\text { Perception } \\
(n, \%)\end{array}$ & $\begin{array}{l}\text { High Risk } \\
\text { Perception } \\
(n, \%)\end{array}$ & $\begin{array}{l}\text { Chi square p- } \\
\text { value }\end{array}$ \\
\hline \multicolumn{4}{|l|}{ Individual Level } \\
\hline $\begin{array}{l}\text { Age } \\
20-27 \text { years } \\
28-33 \text { years } \\
34-45 \text { years }\end{array}$ & $\begin{array}{l}11(27.5) \\
19(47.5) \\
10(25.0)\end{array}$ & $\begin{array}{l}28(21.4) \\
49(37.4) \\
54(41.2)\end{array}$ & 0.179 \\
\hline \multirow{3}{*}{$\begin{array}{l}\text { Ethnicity } \\
\text { Hispanic } \\
\text { Non-Hispanic }\end{array}$} & & & \multirow{3}{*}{0.019} \\
\hline & 108 (82.4) & $26(65.0)$ & \\
\hline & $23(17.6)$ & $14(35.0)$ & \\
\hline \multirow{3}{*}{$\begin{array}{l}\text { Primary Language Spanish } \\
\text { Yes } \\
\text { No }\end{array}$} & & & \multirow[t]{3}{*}{0.003} \\
\hline & $90(68.7)$ & $17(42.5)$ & \\
\hline & $41(31.3)$ & $23(57.5)$ & \\
\hline \multirow{3}{*}{$\begin{array}{l}\text { Personal Control } \\
\text { High } \\
\text { Low }\end{array}$} & & & \multirow{3}{*}{0.347} \\
\hline & $58(50.0)$ & $13(40.6)$ & \\
\hline & $58(50.0)$ & $19(59.4)$ & \\
\hline \multirow{3}{*}{$\begin{array}{l}\text { Optimistic Bias } \\
\text { High } \\
\text { Low }\end{array}$} & & & \multirow{3}{*}{0.196} \\
\hline & $28(25.9)$ & $4(14.3)$ & \\
\hline & $80(74.1)$ & $24(85.7)$ & \\
\hline \multicolumn{4}{|l|}{ Healthcare Related } \\
\hline \multirow{3}{*}{$\begin{array}{l}\text { Use of insulin during pregnancy } \\
\text { Yes } \\
\text { No }\end{array}$} & & & \multirow[t]{3}{*}{0.258} \\
\hline & $85(04.9)$ & $\angle \angle(55.0)$ & \\
\hline & $46(35.1)$ & $18(45.0)$ & \\
\hline \multirow{3}{*}{$\begin{array}{l}\text { Family history of DM2? } \\
\text { Yes } \\
\text { No }\end{array}$} & & & \multirow[t]{3}{*}{0.260} \\
\hline & 69 (52.7) & 17 (42.5) & \\
\hline & $62(47.3)$ & $23(57.5)$ & \\
\hline \multirow{3}{*}{$\begin{array}{l}\text { History of pre-DM2 } \\
\text { or history of high BMI? } \\
\text { Yes } \\
\text { No }\end{array}$} & & & \multirow[t]{3}{*}{0.146} \\
\hline & $10(0.01)$ & $6(15.4)$ & \\
\hline & $121(92.4)$ & $33(84.6)$ & \\
\hline
\end{tabular}

*Bold*: statistically significant at $p<0.10$ 


\begin{tabular}{|c|c|c|c|}
\hline & $\begin{array}{l}\text { Low Risk } \\
\text { Perception } \\
(n, \%)\end{array}$ & $\begin{array}{l}\text { High Risk } \\
\text { Perception } \\
(n, \%)\end{array}$ & $\begin{array}{l}\text { Chi square } p \text { - } \\
\text { value }\end{array}$ \\
\hline \multirow{4}{*}{$\begin{array}{l}\text { Education } \\
\text { Less than High School } \\
\text { High School graduate } \\
\text { Some college or greater }\end{array}$} & & & \multirow[t]{4}{*}{0.018} \\
\hline & $66(50.4)$ & $10(25.0)$ & \\
\hline & $34(26.0)$ & 15 (37.5) & \\
\hline & 31 (23.6) & 15 (37.5) & \\
\hline \multirow{2}{*}{$\begin{array}{l}\text { Income level } \\
<\$ 20,000 \\
>\$ 20,000\end{array}$} & 55 (52.0) & $\begin{array}{l}55(52.0) 55 \\
(52.0)\end{array}$ & \multirow[t]{2}{*}{0.371} \\
\hline & $76(48.0)$ & $20(50.0)$ & \\
\hline \multirow{4}{*}{$\begin{array}{l}\text { Employment } \\
\text { Working (full or part time) } \\
\text { Homemaker } \\
\text { Unemployed or other }\end{array}$} & & & \multirow[t]{4}{*}{0.780} \\
\hline & $51(38.9)$ & $16(40.0)$ & \\
\hline & $54(41.2)$ & $18(45.0)$ & \\
\hline & $26(19.8)$ & $6(15.0)$ & \\
\hline \multirow{3}{*}{$\begin{array}{l}\text { Food insecurity } \\
\text { Yes } \\
\text { No }\end{array}$} & $82(626)$ & $10(175)$ & \multirow[t]{3}{*}{0.089} \\
\hline & & & \\
\hline & 49 (37.4) & $21(52.5)$ & \\
\hline \multirow{5}{*}{$\begin{array}{l}\text { Months Lived in } \\
\text { Neighborhood } \\
0 \text { to } 24 \text { months } \\
25 \text { to } 48 \text { months } \\
49 \text { to } 84 \text { months } \\
85 \text { + months }\end{array}$} & & & \multirow[t]{5}{*}{0.759} \\
\hline & $53(40.4)$ & $19(47.5)$ & \\
\hline & 18 (13.7) & $6(15.0)$ & \\
\hline & $33(25.2)$ & 7 (17.5) & \\
\hline & $27(20.6)$ & $8(20.0)$ & \\
\hline \multirow{5}{*}{$\begin{array}{l}\text { Health Insurance } \\
\text { Medi Cal } \\
\text { Multiple Insurance Plans } \\
\text { A health plan paid for by Medi-cal } \\
\text { Other Public Insurance (SF Health Plan or } \\
\text { Healthy SF) }\end{array}$} & & & \multirow[t]{5}{*}{0.123} \\
\hline & $113(8 / .6)$ & $31(77.5)$ & \\
\hline & $11(8.5)$ & $4(10.0)$ & \\
\hline & $4(3.0)$ & $2(5.0)$ & \\
\hline & $1(0.0)$ & $3(7.5)$ & \\
\hline \multirow{2}{*}{$\begin{array}{l}\text { Migrant Status } \\
\text { Yes } \\
\text { No }\end{array}$} & $110(84.0)$ & $26(65.1)$ & \multirow[t]{2}{*}{0.009} \\
\hline & $21(16.0)$ & $14(35.0)$ & \\
\hline
\end{tabular}

[Table 2] 
Table 3 shows the odds ratios with confidence intervals for the covariates and outcome of risk perception for developing diabetes over the next 1 year. Spanish speakers without family histories of DM2 had a higher likelihood of underestimating their risk $(O R=6.519, p=0.003)$ and had higher odds of reporting lower risk perception. On the other hand, Spanish speakers with family histories of DM2 were more likely to report higher risk perception $(O R=0.16, p=0.028)$. Non Spanish speakers with family histories of $D M 2$ were approximately 3.7 times more likely to report lower risk perception, in contrast to Spanish speakers with family histories of $D M 2(O R=3.68, p=0.028)$. We compared the frequency of reporting lower risk perception Latina and non-Latina Spanish speakers to better understand the distribution of participants who reported Spanish was not their primary language. Amongst the non-Spanish speakers, $40.6 \%$ were Latina and $59.4 \%$ were non-Latina. The frequencies for lower risk perception were similar amongst the two groups, with $65.4 \%$ Latina non-Spanish speakers reporting low risk perception and $63.2 \%$ non-Latina non-Spanish speakers reporting lower risk perception.

Table 3. Odds Ratios with Confidence Intervals for Associations between Covariates and Low Risk Perception for developing Type II Diabetes at 1 year after Delivery; 2017, University of California, San Francisco

\begin{tabular}{|c|c|c|c|}
\hline Variables & Adjusted OR & $95 \% \mathrm{Cl} *$ & p-value \\
\hline $\begin{array}{l}\text { Education } \\
\text { Less than high school education } \\
\text { High school graduate } \\
\text { College education or more }\end{array}$ & $\begin{array}{l}\text { Ref } \\
0.40 \\
0.58\end{array}$ & $\begin{array}{l}\overline{(0.15,1.081)} \\
(0.190,1.739)\end{array}$ & $\begin{array}{l}0.071 \\
0.327\end{array}$ \\
\hline Insulin use during pregnancy & 2.089 & $(0.887,4.913)$ & 0.092 \\
\hline Food insecurity & 0.625 & $(0.287,1.359)$ & 0.236 \\
\hline Spanish Speakers with Family History of DM2 & 0.16 & $(0.031,0.824)$ & 0.028 \\
\hline Spanish speakers with no Family History of DM2 & 6.519 & $(1.894,22.438)$ & 0.003 \\
\hline Non-Spanish Speakers with Family History of DM2 & 3.68 & $(1.149,11.795)$ & 0.028 \\
\hline \multicolumn{4}{|l|}{${ }^{*} \mathrm{Cl}$ : Confidence Interval } \\
\hline *Bold*: statistically significant at $p<0.05$ & & & \\
\hline
\end{tabular}

Other covariates in the model- education, use of insulin during pregnancy and food insecurity- were not statistically associated with low risk perception, however the trends are notable. Women with higher education levels were more likely to have higher risk perceptions $(0.398, p=0.071)$, and women who were food insecure also had higher odds of reporting high risk perception ( $O R=0.625 ; p=0.236)$. In contrast, insulin use during pregnancy did not confer increased risk perception; instead, women who used insulin to manage their gestational diabetes were twice as likely to report low risk perception $(O R=2.1, p=$ 0.092). 


\section{Discussion}

This study presents an exploratory analysis of the complex interplay of individual, healthcare-based and structural factors that are associated with lower risk perception for developing DM2 amongst a primarily migrant and Spanish-speaking population with GDM from San Francisco, CA. Risk perception has been largely understudied in Latino and migrant populations. This is the first paper to specifically analyze risk perception for developing type 2 diabetes amongst primarily Latina women with a known history of GDM.

A key finding from this study is that $76.6 \%$ of participants believed they had low risk for developing DM2 post-partum within the first year after a pregnancy with GDM, and was consistent when asked about risk over 1 year, 5 years and 10 years. These data suggest that in this sample, the high risk of subsequently developing DM2 post-partum and the increasing risk of developing DM2 over time is not well appreciated. Our data suggest that a critical gap exists in the preventive counseling and clinical care specifically for low-income, primarily Latina GDM diagnosed women, and poses a significant public health opportunity to improve education around risk levels and behavioral risk reduction for GDM patients [21].

Our findings are consistent with outcomes reported in similar studies. Two other studies, Kim et al. and Joiner et al., with target populations of Caucasian women in the Netherlands and foreign-born Spanish speaking US Latinos, respectively, reported lower risk perception for developing DM2 [19, 20]. Joiner et al. posit that the low risk perception for developing DM2 amongst a Spanish-speaking migrant population could be due to the differences in judgments of risk, which they suggest is shaped by personal experience and media exposure [20]. Similarly, we hypothesize that risk perception operates through culturally specific pathways, which was assessed through the individual level, healthcare based and structural level covariates in our study.

Given this study sample was $78 \%$ Latina, understanding important cultural and lifestyle-related beliefs of Latina migrants is critical to realizing the disparities in diabetes knowledge and lower perceived risk as demonstrated in our results. Few studies have explored how cultural values, such as susto, fatalismo or simpatia, may influence diabetes risk perceptions and shape how individuals understand, rationalize and internalize their disease risk [30, 31, 32, 33]. These factors could influence the way in which individuals externalize their risk for diabetes, believe in the inevitable nature of the disease, and struggle to control dietary choices when food is an integral part of Latino culture. It is important to explore these factors individually and collectively in how they may or may not shape risk perceptions over the life-course.

Our analyses show that Spanish-speaking women with family histories of DM2 were more likely to correctly assess their higher risk for developing DM2 compared to Spanish speakers with no family history of DM2. This finding underscores that family structures in migrant, Spanish-speaking women may contribute to higher risk perceptions of DM2 compared to that in non-Spanish speakers. We hypothesize that Spanish speakers in this sample, who were primarily migrant women, relied strongly on their families for information about DM2 and chronic disease risk; this was in contrast to non-Spanish speaking women. Experiencing a family member undergo the management and lifestyle changes associated with DM2 could influence the knowledge and perception about the severity of DM2 amongst Spanish 
speaking women with GDM. This is consistent with other studies that identify the key role of health communication within Spanish-speaking families [21]. Non-Spanish speakers with family histories of DM2 were more likely to underestimate their risk perception compared to non-Spanish speakers without family history, perhaps due to the difference in proportion of these two groups. In this sample, there were twice as many Spanish speakers than non-Spanish speakers-we need further studies to evaluate the role of risk perception in non-Spanish speakers. The unique modes in which primary language and family history of disease intersect are critical to gain a deeper understanding differences in risk perception of disease between Spanish and non-Spanish speakers. Education level, food insecurity, and insulin use during pregnancy were not significantly associated with the outcome

Future qualitative studies could explore the reasons underlying patients' low risk perception - which could include healthcare providers' limitations in clearly communicating and confirming the patients' understanding of their disease, and patients' fears, cultural and religious beliefs that might affect their risk perceptions. Moreover, further research within this population about the immediate barriers to healthy lifestyles post-partum are key to realizing what factors influence their long term risk perception.

Strengths and Limitations

To our knowledge, this is the first study to describe risk perception for developing diabetes, and the associated factors, within a primarily Spanish-speaking, majority migrant group with GDM. The strengths of this study were that it included a primarily Latina population and assessed risk perception through a critical structural lens to better understand underlying factors, beyond demographic and health-related, that may influence risk perception. The results highlight the gaps in clinical and public health knowledge regarding risk perception among this population, and the importance of clear and culturally-informed counseling around risk for Spanish-speaking, migrant GDM patients.

A constraint of this analysis was the small sample size of 171 women, which minimized statistical power. A larger sample size may have allowed for further subgroup comparisons and larger cell size to improve precision of estimates. However, the study design goals did not include these factors as the study was designed to deliver an intervention to the target population. While this study is not generalizable to all women with GDM, it is generalizable to GDM women who are primary Latina and are facing economic hardship in safety net and prenatal settings in Northern California.

Public Health Implication

There is a critical public health and clinical need for improved counseling about risk of DM2 for women with GDM, specifically migrant, Spanish speaking women. Understanding that risk perception is multidimensional and affected by individual, health-care and structural factors is key to developing educational tools for various groups. The clinical implications of this involve: 1) improved counseling around risk for developing DM2 for migrant women with GDM, 2) training for clinicians and healthcare providers that is grounded in both epidemiological evidence and sociological theories and 3) targeted interventions for Latina women lacking family histories of DM2 to encourage preventive behaviors after a 
GDM pregnancy. Using an adapted framework to understand risk perception can help clinicians to understand and address the multidimensional needs of a specific population, such as Latina patients. The ultimate goal of this research is to develop culturally-informed interventions that promote appropriate risk perception for women with GDM to motivate positive health behaviors post-partum and minimize risk for developing DM2.

\section{Conclusions}

The results of this study highlight the gaps in clinical and public health knowledge regarding risk perception among this population, and the importance of clear and culturally-informed counseling around risk for Spanish-speaking, migrant GDM patients. Spanish speaking women without family history of DM2 had a lower risk perception than Spanish speaking women with family histories of DM2. Further qualitative research on the factors contributing to lower risk perception amongst these groups is necessary to better design targeted interventions.

\section{Declarations}

\section{Ethics Approval and Consent to Participate}

This study was approved and reviewed by the University of California San Francisco Institutional Review Board. The clinical trial registration number is: NCT02240420.. All participants received informed consent.

\section{Consent for Publication}

Authors provide consent for publication.

\section{Availability of Data and material}

The dataset supporting the conclusions of this article is available in the University of California, San Francisco Department of Epidemiology and Biostatistics repository, and available upon reasonable request to the author.

\section{Competing Interests}

The authors declare that they have no competing interests. 


\section{Funding}

Financial support for this study was made possible by research study grants by the University of California Berkeley and University of California San Francisco.

\section{Author Contributions}

PA designed and conceived of the study question with guidance and mentorship from $\mathrm{MH}, \mathrm{SG}, \mathrm{ML}$ and NP. ML assisted with data analysis and statistical technique. MH guided the development of the conceptual framework. NP, KSG, ML and MH were all involved in editing, revising and reviewing the various versions of the paper.

\section{Acknowledgments}

We'd like to acknowledge the STAR MAMA research team, and participants in the STAR-MAMA intervention for participation in this study. We'd like to thank our funding sources: UCSF Dean's Summer Research Grant, the National Institutes of Health, National Center on Minority Health and Health Disparities P60MD006902; the National Institutes of Health, National Institute of Diabetes and Digestive and Kidney Diseases P30DK092924 and the National Center for Advancing Translational Sciences, National Institutes of Health, through UCSF-CTSI Grant Number UL1 TR000004. The contents of this paper are solely the responsibility of the authors and do not necessarily represent the official views of the $\mathrm{NIH}$.

\section{Author's Information}

Priyanka Athavale received her M.S. from the University of California, Berkeley in Human and Health Sciences, as part of the Joint Medical Program. She is a M.D. Candidate at University of California, San Francisco School of Medicine (UCSF). Her mentors, Dr. Margaret Handley, Dr. Karen Sokal-Gutierrez, Dr. Ndola Prata and Dr. Maureen Lahiff are co-authors and sources of guidance and mentorship for this paper.

\section{Abbreviations}

STAR MAMA 
support via Telephone Advice and Resources/Sistema Teléfonico de Apoyo y Recursos-MAMA GDM

gestational diabetes mellitus

DM2

type 2 diabetes

Pre-DM

pre-diabetes

ZSFGH

Zuckerberg San Francisco General Hospital

$\mathrm{BMI}$

body mass index

US

United States

\section{References}

1. DeSisto CL, Kim SY, Sharma AJ. Prevalence estimates of gestational diabetes mellitus in the United States, Pregnancy Risk Assessment Monitoring System (PRAMS), 2007-2010. Prev Chronic Dis. 2014;11(12), E104. http://doi.org/10.5888/pcd11.130415.

2. Mukerji, G., Kainth, S., Pendrith, C., Lowe, J., Feig, D. S., Banerjee, A. T., ... Lipscombe, L. L. (2016). Predictors of low diabetes risk perception in a multi-ethnic cohort of women with gestational diabetes mellitus. Diabetic Medicine, 33(10), 1437-1444. http://doi.org/10.1111/dme.13009

3. Bellamy L, Casas J-P, Hingorani AD, Williams D. Type 2 diabetes mellitus after gestational diabetes: a systematic review and meta-analysis. Lancet. 2009;373(9677):1773-9.

4. Xiang, A. H., Li, B. H., Black, M. H., \& Sacks, D. A. (2011). Racial and ethnic disparities in diabetes risk after gestational diabetes mellitus, 3016-3021. http://doi.org/10.1007/s00125-011-2330-2

5. Ferrara, A., Peng, T., \& Kim, C. (2008). Trends in Postpartum Diabetes Screening and Subsequent Diabetes and Impaired Fasting Glucose Among Women With Histories of Gestational Diabetes Mellitus: A report from the Translating Research Into Action for Diabetes (TRIAD) Study. Diabetes Care,32(2), 269-274. doi:10.2337/dc08-1184 
6. Feig, D. S., Zinman, B., Wang, X., \& Hux, J. E. (2008). Risk of development of diabetes mellitus after diagnosis of gestational diabetes. Canadian Medical Association Journal,179(3), 229-234. doi:10.1503/cmaj.080012

7. McCurley, J. L., Fortmann, A. L., Gutierrez, A. P., Gonzalez, P., Euyoque, J., Clark, T., ... Gallo, L. C. (2017). Pilot Test of a Culturally Appropriate Diabetes Prevention Intervention for At-Risk Latina Women. The Diabetes Educator, 14572171773802.

8. Chasan-Taber, L., Marcus, B. H., Rosal, M. C., Tucker, K. L., Hartman, S. J., Pekow, P., ... Markenson, G. (2015). Proyecto Mamá: A lifestyle intervention in overweight and obese Hispanic women: A randomised controlled trial - study protocol. BMC Pregnancy and Childbirth, 15(1).

http://doi.org/10.1186/s12884-015-0575-3

9. Bardenheier BH, Imperatore G, Gilboa SM, Geiss LS, Saydah SH, Devlin HM, Kim SY, Gregg EW. Trends in Gestational Diabetes Among Hospital Deliveries in 19 U.S. States, 2000-2010. Am J Prev Med. 2015 Jul;49(1):12-9. doi:10.1016/j.amepre.2015.01.026.

10. Ferrara, A., Hedderson, M. M., Albright, C. L., Ehrlich, S. F., Quesenberry, C. P., Peng, T. Crites, Y. (2011). A Pregnancy and Postpartum Lifestyle Intervention in Women With Gestational Diabetes Mellitus Reduces Diabetes Risk Factors: A feasibility randomized control trial. Diabetes Care,34(7), 15191525. doi:10.2337/dc10-2221

11. Athavale, P., Thomas, M., Delgadillo-duenas, A. T., Leong, K., Najmabadi, A., Harleman, E., ... Handley, M. A. (2016). Linking High Risk Postpartum Women with a Technology Enabled Health Coaching Program to Reduce Diabetes Risk and Improve Wellbeing: Program Description, Case Studies, and Recommendations for Community Health Coaching Programs, 2016. http://doi.org/10.1155/2016/4353956

12. Heatley, Emer, et al. "The DIAMIND study: postpartum SMS reminders to women who have had gestational diabetes mellitus to test for type 2 diabetes: a randomised controlled trial - study 
protocol." BMC Pregnancy and Childbirth, vol. 13, no. 1, Dec. 2013, doi:10.1186/1471-2393-13-92.

13. Ryswyk, Emer Van, et al. "Womens views and knowledge regarding healthcare seeking for gestational diabetes in the postpartum period: A systematic review of qualitative/Survey studies." Diabetes Research and Clinical Practice, vol. 110, no. 2, 2015, pp. 109-122., doi:10.1016/j.diabres.2015.09.010.

14. Gabbe, S. G., Landon, M., Warren-Boulton, E., \& Fradkin, J. (2012). Promoting Health After Gestational Diabetes: A National Diabetes Education Program Call to Action. Obstetrics and Gynecology,

119(1), 171-176. http://doi.org/10.1097/AOG.0b013e3182393208

15. Janz, N. K., \& Becker, M. H. (1984). The Health Belief Model: A Decade Later. Health Education Quarterly,11(1), 1-47. doi:10.1177/109019818401100101

16. Vlaar, E. M., Nierkens, V., Nicolaou, M., Middelkoop, B. J., Stronks, K., \& Valkengoed, I. G. (2014). Risk perception is not associated with attendance at a preventive intervention for type 2 diabetes mellitus among South Asians at risk of diabetes. Public Health Nutrition,18(06), 1109-1118. doi:10.1017/s1368980014001086

17. Noar SM, Zimmerman RS. Health Behavior Theory and cumulative knowledge regarding health behaviors: are we moving in the right direction? Health education research. 2005; 20(3):275-290.

18. Vadheim, L. M., Mcpherson, C., Kassner, D. R., Vanderwood, K. K., Hall, T. O., Butcher, M. K., . . Harwell, T. S. (2010). Adapted Diabetes Prevention Program Lifestyle Intervention Can Be Effectively Delivered Through Telehealth. The Diabetes Educator,36(4), 651-656. doi:10.1177/0145721710372811

19. Kim, C., Mcewen, L. N., Piette, J. D., Goewey, J., Ferrara, A., \& Walker, E. A. (2007). Risk Perception for Diabetes Among Women With Histories of Gestational Diabetes Mellitus. Diabetes Care,30(9), 22812286. doi: $10.2337 / \mathrm{dc} 07-0618$ 
20. Joiner, K. L., Sternberg, R. M., Kennedy, C. M., Fukuoka, Y., Chen, J., \& Janson, S. L. (2016). Perception of Risk for Developing Diabetes Among Foreign-Born Spanish-Speaking US Latinos. The Diabetes Educator,42(4), 418-428. doi:10.1177/0145721716646204

21. Tang, J. W., Foster, K. E., Pumarino, J., \& Cameron, K. A. (2015). Perspectives on Prevention of Type 2 Diabetes After Gestational Diabetes: A Qualitative Study of Hispanic , African-American and White Women. Maternal and Child Health Journal, 1526-1534. http://doi.org/10.1007/s10995-014-1657-y

22. Brown, S. L., \& Morley, A. M. (2007). Risk perception, fuzzy representations and comparative optimism. British Journal of Psychology,98(4), 575-587. doi:10.1348/000712606x169020

23. Janz, N. K., \& Becker, M. H. (1984). The Health Belief Model: A Decade Later. Health Education Quarterly,11(1), 1-47. doi:10.1177/109019818401100101

24. Solar O, Irwin A. A conceptual framework for action on the social determinants of health. Social Determinants of Health Discussion Paper 2 (Policy and Practice). WHO 2010

25. Handley, M. A., Harleman, E., Gonzalez-mendez, E., Stotland, N. E., Althavale, P., Fisher, L., ... Rios, C. (2016). Applying the COM-B model to creation of an IT-enabled health coaching and resource linkage program for low-income Latina moms with recent gestational diabetes: the STAR MAMA program. Implementation Science, 1-15. http://doi.org/10.1186/s13012-016-0426-2

26. The Diabetes Prevention Program (DPP): Description of lifestyle intervention. (2002). Diabetes Care,25(12), 2165-2171. doi:10.2337/diacare.25.12.2165

27. ACOG Practice Bulletin No. 190. (2018). Obstetrics \& Gynecology, 131(2), e49-e64. https://doi.org/10.1097/aog.0000000000002501 
28. Walker EA, Mertz CK, Kalten MR, Flynn J. Risk perception for developing diabetes -comparative risk judgments of physicians. Diabetes Care. 2003; 26:2543-2548.

29. Shim JK. (2005). Constructing 'race' across the science-lay divide: Racial formation in the epidemiology and experience of cardiovascular disease. Social Studies of Science, 35(3), 405- 436.

30. Hatcher, E., \& Whittemore, R. (2007). Hispanic adults? beliefs about type 2 diabetes: Clinical implications. Journal of the American Academy of Nurse Practitioners,19(10), 536-545. doi:10.1111/j.1745-7599.2007.00255.x

31. Caballero, A. E. (2007). Cultural Competence in Diabetes Mellitus Care: An Urgent Need. Insulin, 2(2), 80-91. http://doi.org/10.1016/S1557-0843(07)80019-4

32. Caballero, A. E. (2011). Understanding the Hispanic/Latino patient. American Journal of Medicine, 124(10 SUPPL.), S10-S15. http://doi.org/10.1016/j.amjmed.2011.07.018

33. Caban, A., \& Walker, E. A. (2006). A Systematic Review of Research on Culturally Relevant Issues for Hispanics With Diabetes. The Diabetes Educator, 32(4), 584-595. https://doi.org/10.1177/0145721706290435

\section{Figures}




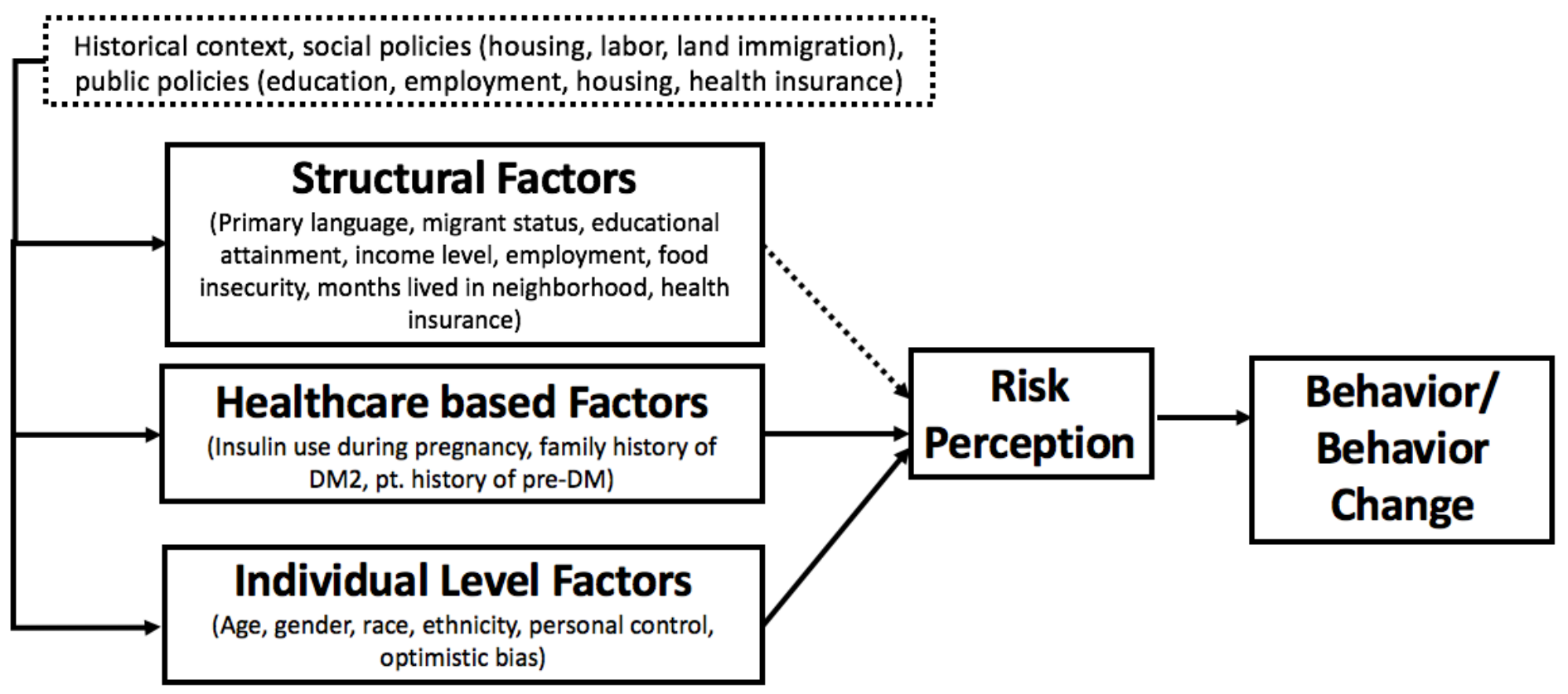

Figure 1

Conceptual Framework Linking Structural, Healthcare based and Individual Factors to Risk Perception; 2017, University of California, San Francisco 